\title{
Correspondence
}

\section{Future of British Paediatric Association}

Sir,

At the risk of being accused of washing our linen in public, could I draw the attention of British paediatricians to the fact that our specialty, by continuing to toy with the idea of setting up our own College, is likely to end up with the worst of all outcomes: unpopularity within the Royal College of Physicians and no home of our own. To set up a College of Paediatricians would involve a change in the Constitution and style of the British Paediatric Association (which was founded, in emulation of the Association of Physicians, for the sharing of knowledge and the promotion of good fellowship); setting up our own examination for Membership/Fellowship, severing our links with adult medicine just when they need strengthening and developing, foregoing the privileges of belonging to an ancient and powerful body for the doubtful benefits of independence, being responsible for a further fragmentation of medicine as a political lobby when we need to speak with a single voice, and dividing our own membership. But if we want to stay in the fold of the Royal College of Physicians, we must stop behaving like the black sheep of the family and show proper appreciation of what has been done in recent years by our colleagues working in other branches of general medicine to accommodate us both literally and figuratively. The year of the Cleveland inquiry is not one in which the more diffident among us would like to assert our claim to be the principal voice for the rights and wellbeing of children in our society; yet the voices of those who call for the establishment of a College of our own seem to be those with this large view of our responsibilities. In fact a College of Paediatricians could not even claim to speak for all those who care for children in the hospital service, many of whom owe allegiance to other Colleges - of Surgery, Psychiatry, Pathology, etc-quite apart from the important role of those engaged in primary care and those who work in disciplines ancillary to our practice or in other fields of child care altogether.

In short, the establishment of our own College would be a divisive, expensive, and hazardous enterprise at a time when our parent College is doing its best to accommodate itself to our needs; yet if we hesitate longer, our position there may become untenable. We don't need more confusing plebiscites but a firm lead from our elected officers in one direction or the other with no turning back once we have set out. If we stay within the Royal College of Physicians, we need to stop whining and negotiate with its officers on the basis of clearly stated and defensible proposals.

If we opt for a Faculty it should only be on the basis that all other groupings within the Royal College of Physcians should follow suit; if not we should retain our present status as full members of the College, which then might be prepared to adjust its Constitution to make sure that its paediatric committee could be seen to be truly representative of the body of consultant paediatricians. It could even be that by convention a paediatrician would normally be elected as Second Vice President to make sure that we are always represented among the College Officers. The wrong decision could have a permanently damaging effect on paediatrics as a specialty within medicine-so much so that I suggest that we revert to calling ourselves physicians for children.

\section{J A DAvis \\ University of Cambridge Clinical School, Department of Paediatrics, Addenbrooke's Hospital, Hills Road, Cambridge CB2 $2 Q Q$}

\section{Professor Baum comments:}

I write in response to Professor Davis' crie de coeur. I know how sincerely he believes paediatricians belong within the Colleges of Physicians and that we should be appreciative of the generous hospitality we have received and may hope to enjoy in the future. I do, however, find myself in disagreement with his point of view and take exception to the tone of his arguments urging us to desist from whining, from toying with ideas of independence and from behaving like black sheep, while advising us to stay in the fold and be grateful for the privileges we have been allowed. I object in particular to his reference to the Cleveland inquiry, thereby disparaging his paediatric colleagues in a wholesale manner. I have a higher opinion of British paediatricians and believe in our natural growth and development towards independence.

Only by establishing an independent college will children's medicine in this country have a strong and independent voice on an equal footing with the medicine of adulthood, surgery, obstetrics, and psychiatry. Thereby we will have the negotiating rights on behalf of children and the authority to advocate their needs with the maximum clarity to government and the public at large.

Paediatrics and Child Health have grown to be substantially different from general medicine and now need to be seen as such in the same way that obstetrics and gynaecology are seen to be different from general surgery. Our independent identity would enable us to form authoritative links with obstetrics, surgery, anaesthetics, pathology, psychiatry, general practice, and other diverse professional bodies in addition to our valued links with internal medicine. Moreover, the nature of our subject requires postgraduate examinations designed by paediatricians and doctors working in Child Health, reflecting the philosophy, attitudes, and practices of children's medicine, freed from the progressively inappropriate framework of the medicine of adulthood.

Our paediatric colleagues in the United States share 
none of Professor Davis' qualms about their identity. Their voice in the world of medical science and in the corridors of power in Washington is clear and strong. Our colleagues in Europe unashamedly identify paediatrics as a science and profession looking, with a particular eye to 1992, for counterpart cooperation from the highly respected and reputed body of paediatricians in this country. Our colleagues in more distant parts of the world turn to British paediatricians for leadership and support in their clinical and political struggles for the betterment of their children's health. The formation of an independent college for paediatricians and those involved in children's health work would, I believe, be universally welcomed.

I would like to agree with Professor Davis on one point. We should indeed look for and confidently follow the firm leadership of our elected officers whose discussion document on proposals for a college is currently in its final stages of preparation.

\section{Reflex anal dilatation associated with severe chronic constipation}

Sirs,

The flurry of publications in both the medical and the popular press about the significance, or otherwise, of reflex anal dilatation is serving only to confuse the issue further, and to compromise the position of careful and caring doctors who are doing their best to help abused children and their families.

The article by Clayden appears to imply that a visibly relaxed sphincter is synonymous with reflex anal dilatation. ${ }^{1}$ We know that a lax anal sphincter occurs in the absence of reflex anal dilatation. Is a lax sphincter the same as a visibly relaxed sphincter?

The children described in Clayden's series had all been subjected to invasive techniques of management, including suppositories, enemas, anal dilatation under anaesthesia, anoplasty and, in two children, internal anal sphincterotomy. It is therefore hardly surprising that $15 \%$ of these children showed 'a relaxed sphincter'. They were the subjects of trauma similar to that associated with anal abuse. Surely the lesson to be learnt from this finding is that it is unsafe to diagnose sexual abuse on the basis of anal dilatation in a child who is clearly grossly constipated, and who has been subjected to anal penetration. Reflex anal dilatation is a physical sign and like all physical signs has a differential diagnosis, in this instance including anal abuse.

It is time that some precision is brought into the terminology of reflex anal dilatation so that we can be certain that we are all talking about the same thing. From the present literature, it is often difficult to know whether authors are referring merely to relaxation of the external sphincter, to a lax sphincter, or to reflex anal dilatation. This type of misunderstanding may be the basis for the claim that reflex dilatation is a commonly seen and unimportant finding. ${ }^{2}$ Such a view seems to be favoured by doctors dealing mainly with adult patients. Few, if any, paediatricians claim to see gross reflex dilatation fre- quently, unless in anally abused children. Any description of reflex anal dilatation should include the actual measurement of the diameter of the open anal canal, together with a description of both the persistence, and the reproducibility of the sign. It is vital that such documentation is given so that the importance of the data can be assessed.

\section{References \\ ${ }^{1}$ Clayden GS. Reflex anal dilatation associated with severe chronic constipation. Arch Dis Child 1988;63:832-6. \\ 2 Heald RJ. Child abuse. Br Med J 1988;297:421.}

B L PRIESTLEY and L S TAITZ

The Children's Hospital, Sheffield S10 2TH

\section{Dr Clayden comments:}

Sadly this letter reflects the unhealthy attitude that criticism of scientific detail is identical to opposition to the whole movement to reduce child sexual abuse. The 'flurry of publications' is symptomatic of the previous dearth of evidence on the reliability of the anal signs of child sex abuse and of information about those conditions which might mimic these signs. My publications were an attempt to warn those careful and caring doctors not to compromise themselves by trusting to signs which may mislead them. ${ }^{12}$ Apart from the obvious trauma to the children and families, incorrect diagnosis of sex abuse sets back the whole momentum of vigilance and credibility in the population in general.

Either my lack of clarity or Priestley and Taitz's cognitive disonance has led to a degree of misunderstanding. They have read the surgical interventions given in table 5 as having occurred before presentation to my clinic whereas it describes the treatment given on diagnosis and was included to emphasise the severity of the chronic constipation in this group. All but three of the children with a visibly relaxed sphincter had had invasive anal treatment before presentation to my clinic (table 4), however, I know of recent cases where child sex abuse was confidently diagnosed on anal findings despite clear histories of invasive anal procedures.

Priestley and Taitz reasonably object to my use of the term 'visibly relaxed sphincter'. This was the term I had used at the beginning of this decade to collect the data and therefore it is accurate to describe it as such. In a small prospective study of the appearance of the anus in similarly chronically constipated children I found a number with a visibly lax sphincter who on occasions had reflex anal dilatation and on other occasions had a normal appearance. I agree that it is time for a proper definition based on accurate measurement of size and time.

As the rectoanal reflex is an essential part of the physiology of all but those with Hirschsprung's disease, the appearance of reflex anal dilatation is inevitable if the external sphincter is held apart (it fatigues in approximately 30 seconds in most subjects) and the rectum contains a stool which evokes the rectoanal reflex. Obviously if the external anal sphincter is damaged by frequent buggery this reflex is likely to be more apparent but so it will be if the child has not practised using the external sphincter. 